\title{
INADEQUATE CASES OF INTERVENTION IN ARCHITECTURAL HERITAGE BUILDINGS IN MEXICO AFTER THE SEPTEMBER 2017 EARTHQUAKES
}

\author{
FERNANDO PEÑA ${ }^{1 *}$ AND MARCOS M. CHÁVEZ ${ }^{1}$ \\ ${ }^{1}$ Instituto de Ingeniería \\ Universidad Nacional Autónoma de México \\ Ciudad Universitaria, 04510 Mexico City, Mexico \\ e-mail: fpem@pumas.iingen.unam.mx, mchavezc@iiingen.unam.mx,www.iingen.unam.mx
}

Keywords: Historical Structure, Architectural Heritage, Structural Intervention, Earthquake

\begin{abstract}
The two large-scale earthquakes that occurred on September 7 (Mw 8.2) and 19 (MW 7.1), 2017 in Mexico left 2,340 damaged architectural heritage buildings throughout the country. Due to the large amount of architectural heritage buildings damaged, the government department responsible for protecting the architectural heritage and the practitioners specialized in conservation was overwhelmed. Therefore, it was necessary to incorporate practitioners who are not specialized in conservation, first to attend the emergency works and later into structural intervention works. In this way, this paper presents some examples of emergency work, as well as intervention proposals that have been inadequate. The common errors observed in emergency works are discussed, as well as the application of erroneous or inadequate concepts in intervention proposals. Comparison with correct intervention works are also presented.
\end{abstract}

\section{INTRODUCTION}

The architectural heritage in Mexico is wide, rich and varied. It has more than 50,000 archaeological sites and 110,000 buildings built between $16^{\text {th }}$ and $19^{\text {th }}$ centuries; as well as 35 sites inscribed on the UNESCO World Heritage List. The two large-scale earthquakes that occurred on September 7 (Mw 8.2) and 19 (Mw 7.1), 2017 in Mexico left 2,340 damaged architectural heritage buildings throughout the country; which corresponds around $6 \%$ of the total of architectural heritage buildings located in the affected area.

The earthquake of September 7, with a magnitude Mw 8.2, occurred at 23:49:17 local time. The epicenter was located in the Gulf of Tehuantepec, $133 \mathrm{~km}$ southwest of Pijijiapan, Chiapas and $700 \mathrm{~km}$ from Mexico City. This event was cataloged by the National Seismological Service (SSN) as normal failure and is the largest recorded in the country. The maximum accelerations recorded in the field were higher than $228 \mathrm{Gal}$ [1]. On the other hand, the earthquake of September 19 occurred at 13:14:40 local time, with a magnitude $\mathrm{Mw}$ 7.1. The epicenter was located on the border between the states of Puebla and Morelos, $12 \mathrm{~km}$ southeast of Axochiapan, Morelos and $120 \mathrm{~km}$ from Mexico City. According to the SSN, it was an intraplate earthquake of normal failure. According to official records, the maximum accelerations recorded in the field were greater than 220 Gal, in the epicentral zone [2]. 
Due to the large amount of architectural heritage buildings damaged, the government department responsible for protecting the architectural heritage and the practitioners specialized in conservation were overwhelmed. Therefore, it was necessary to incorporate practitioners who are not specialized in conservation, as well as volunteers from communities with little or no supervision of engineers or architects, first to attend the emergency works and later into structural intervention works. In this way, this paper presents some examples of emergency work, as well as intervention proposals that have been inadequate. The common errors observed in emergency works are discussed, as well as the application of erroneous or inadequate concepts in intervention proposals. Comparison with correct intervention works are also presented.

\section{EMERGENCY WORKS}

One of the first activities in a structure damaged by an earthquake is to carry out emergency works, to avoid collapse of the damaged areas. The objective of emergency works are to improve the stability conditions of the damaged structure, to resist, not only the own weight of the structure, but also accidental loads that may occur before or during the restoration works, such as the aftershocks [3-6]. For example, figure 1a shows the damage tower of the temple of Pilcaya, Puebla after the earthquake. It can be observed that although the tower had severe damage, it did not collapse. Few days later, before the emergency works began, the tower collapsed, standing only part of the first body of the tower (figure 1b). It seems that the cause

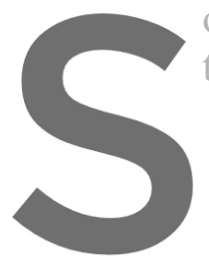
of the collapse was the to the temple.

\section{Register for free at https//www.scipedia.com to}
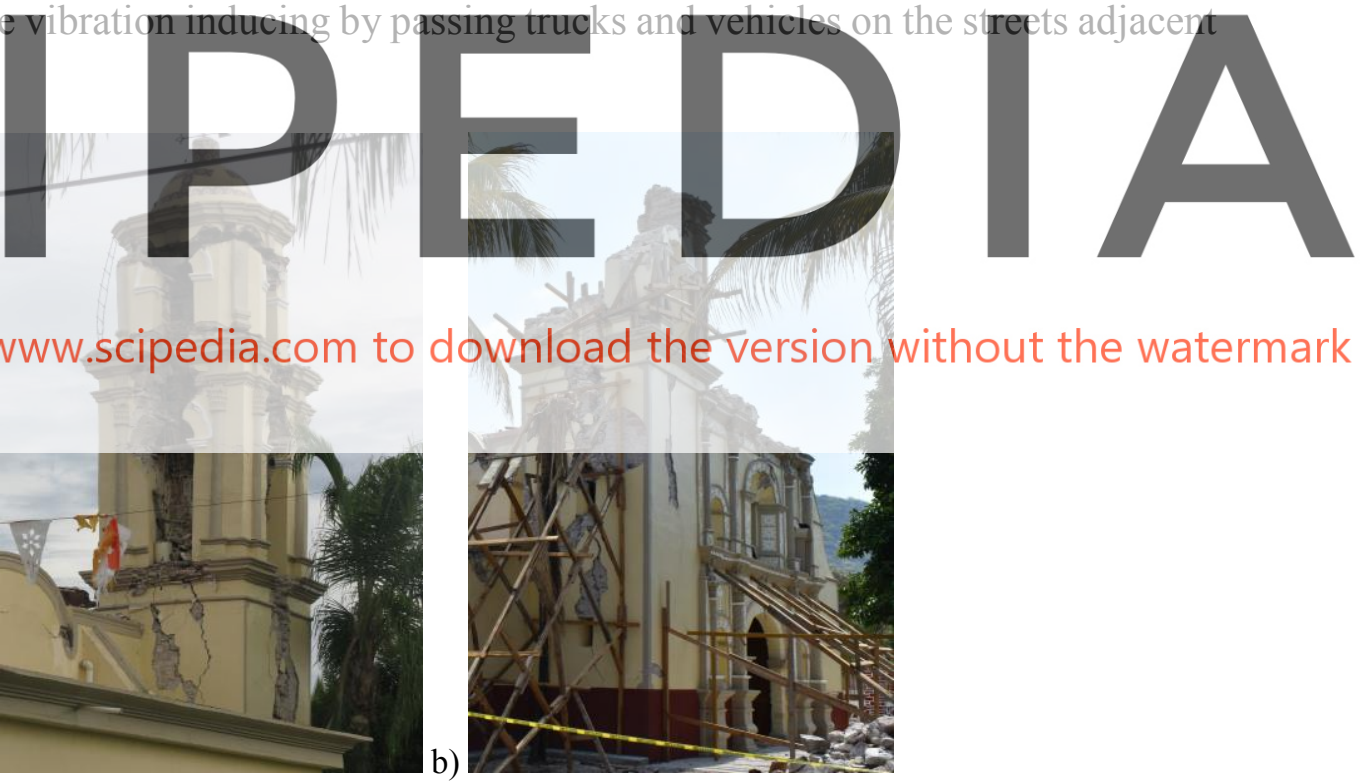

Figure 1: Damaged tower of temple of Pilcaya, Puebla: a) after earthquake; b) few days after the seismic event

Due to the urgency of keeping damaged structures standing, emergency work is often carried out by volunteers from communities with little or no supervision of engineers or architects. Because of this, solutions that do not increase the structural capacity of the building are often implemented. In most of these cases, it is believed that emergency works only serves to support the weak parts of the structure that are in danger of collapse. 
Figure 2 shows the Municipal Palace of Hueyapan, Morelos after the earthquake. The building was made with unreinforced brick masonry. The loss of the lower archway is observed, which puts the stability of the balcony at risk. In the upper part, diagonal shear cracks are observed. It is noted that the balcony shoring system is not adequate, as the struts will not be able to withstand lateral forces in case of an aftershock. In this particular case, the shoring system was thought only for vertical forces.

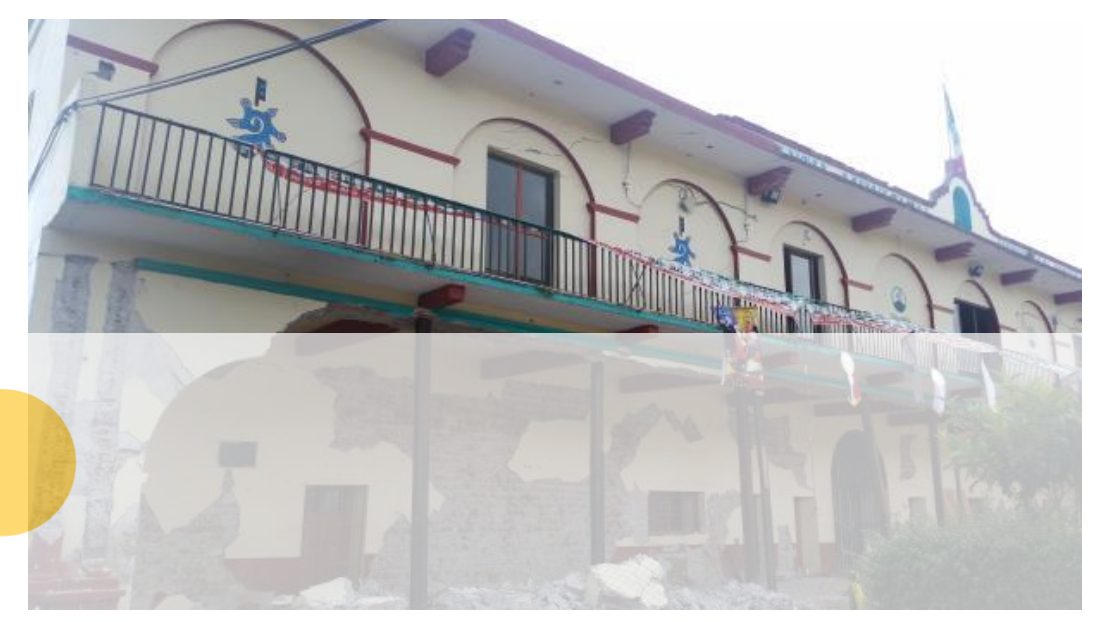

Figure 2: Municipal Palace of Hueyapan, Morelos
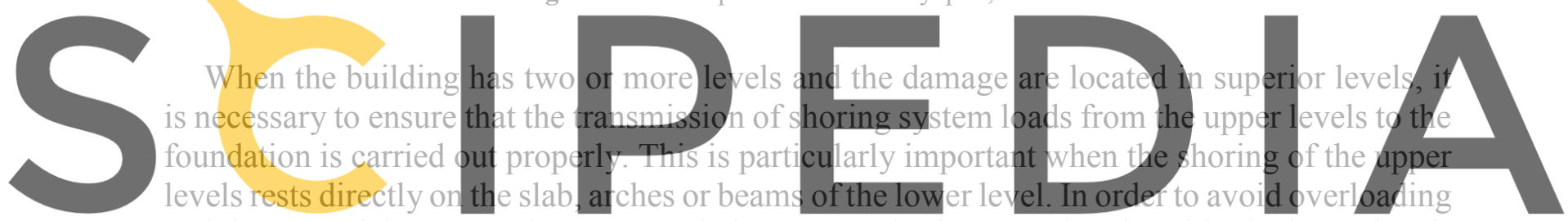

and damage of the supporting structural elements, a shoring must be placed in the lower levels

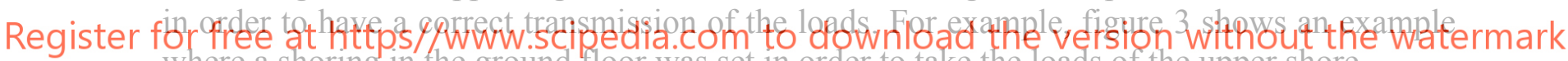
where a shoring in the ground floor was set in order to take the loads of the upper shore.

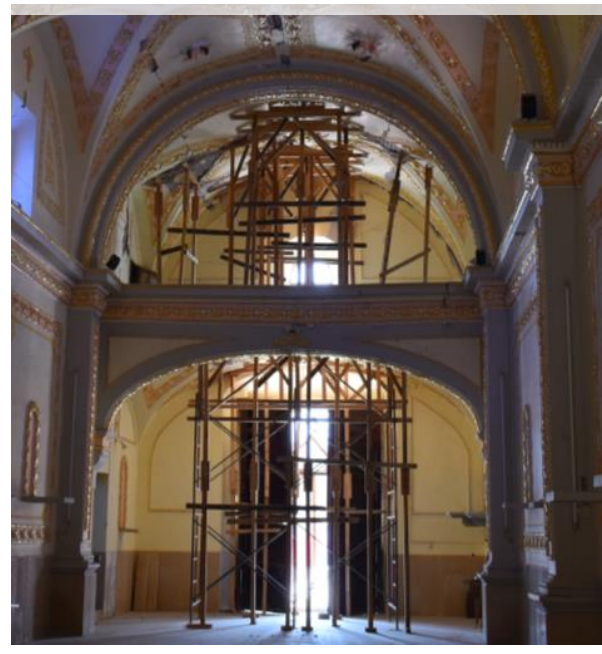

Figure 3: Example of a correct transmission of shoring system loads of higher than lower levels 
The shoring system is a temporary system that must be removed when the intervention works are finished. Wood is the most common material used for shoring system due its versatility, manageability, ease of construction and cheap. However, good quality wood must be used; as well as particular attention to the connections must be paid. The quality of the wood is with regard to: material (use of structural wood), element (no slender elements or buckling elements) and structural system (strength capacity). In the case of wooden elements, the most common practice is to build a wooden truss support (figure 4a). In other cases, especially when the height of building is considerable, as in churches, a steel shoring system (fig. 4b) or mixed system of steel and wood are used (fig. 4c).
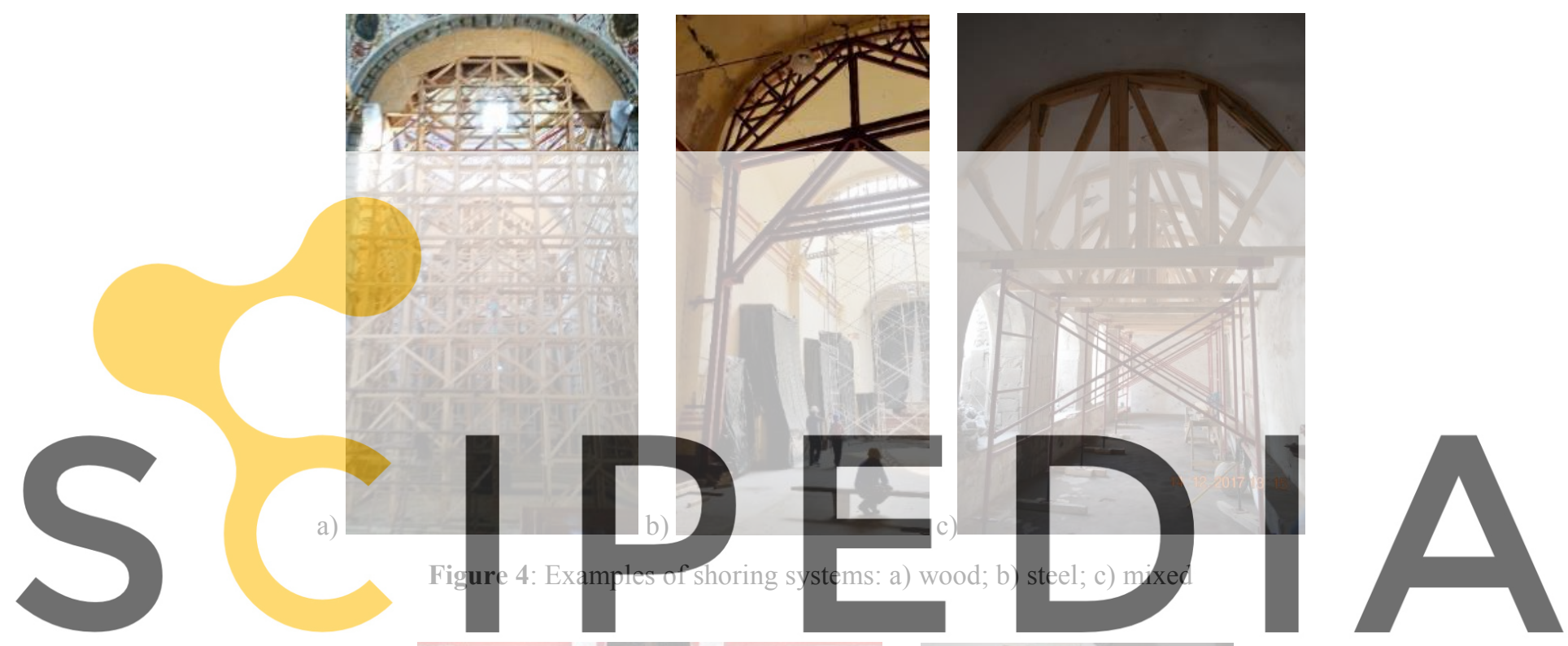

Register for free at https//www.scipedia.com to download the version without the watermark

a)

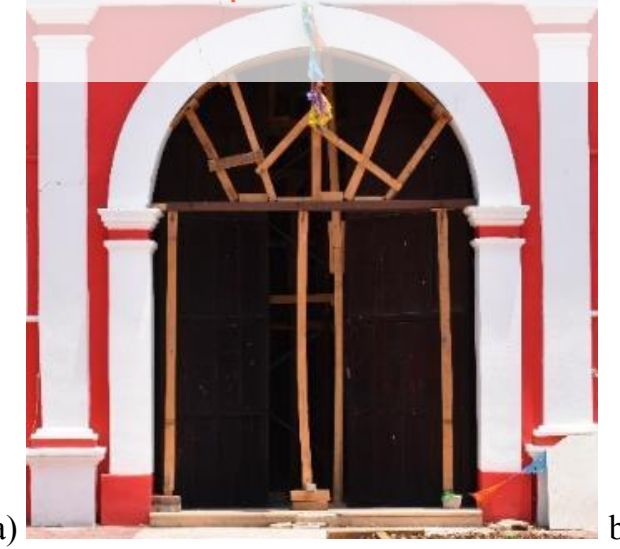

b)

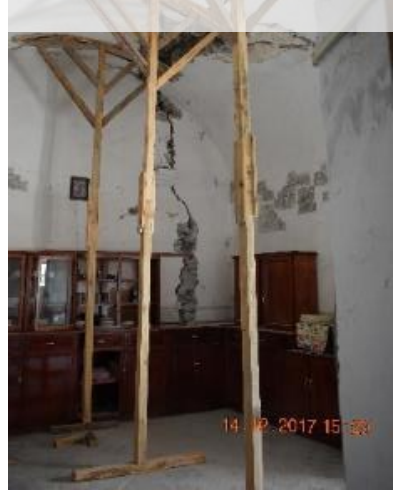

Figure 5: Example of bad quality wooden elements: a) buckled element; b) slender elements

Figure 5 shows two example of a bad quality of wooden systems. In figure $5 \mathrm{a}$, it can see that one of the vertical element is buckling, reducing its structural capacity. Additionally, vertical elements are not high enough, so brick pieces were used at the base, to increase their height. 
Figure $5 \mathrm{~b}$ shows an example of a scarce shoring system, where slender elements are used. It is clear that this system is unable to take lateral and vertical forces.

Due to the lack of experience and non-engineering criteria, there are cases in which there is a waste of economic and material resources, as well as workmanship, which can be used in other damage buildings. For example, there are cases with an excessive shoring, preventing people from entering the building. In these cases, part of the scaffolding must be dismantled before an intervention process, in order to have space to start the intervention works. There are also cases, in which the shoring is placed directly over a crack, so it will be necessary to remove it in case of an intervention (fig. 6). For this reason, it is important to make a preliminary structural analysis to determine the characteristics of the shoring system and as far as possible, place it so that it does not interfere with the intervention works.

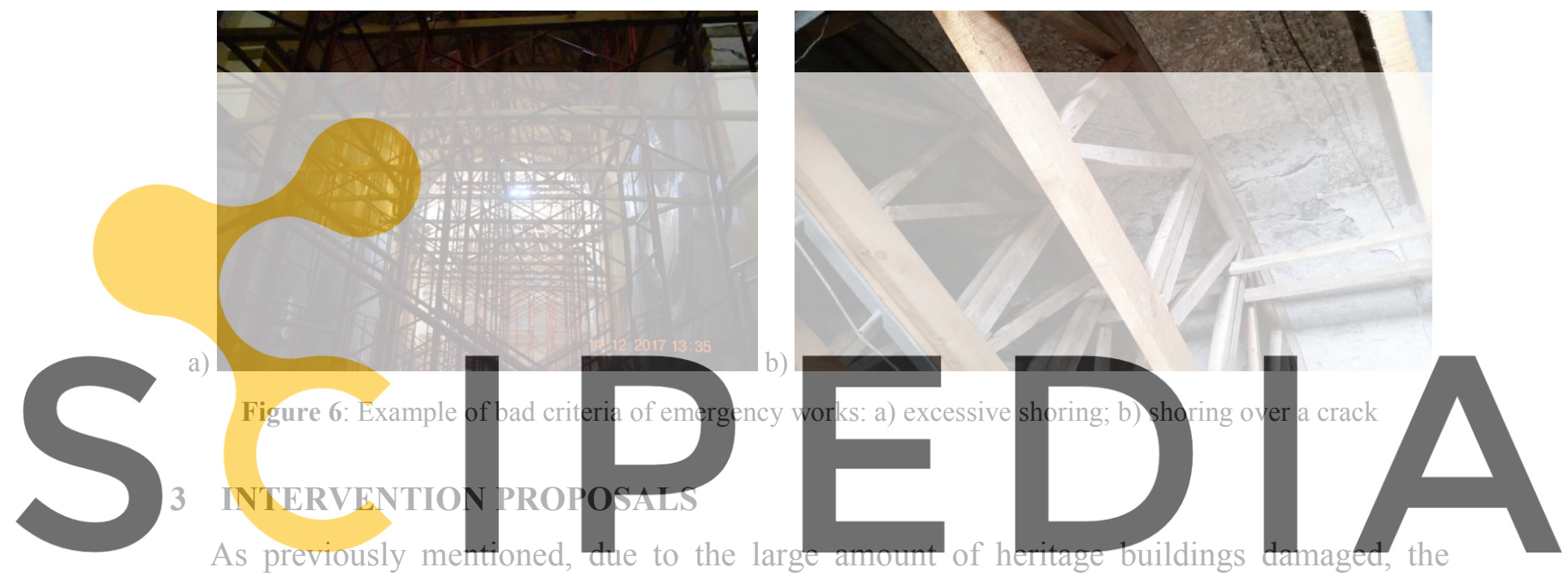

government and the practitioners specialized in conservation were overwhelmed. Therefore, it

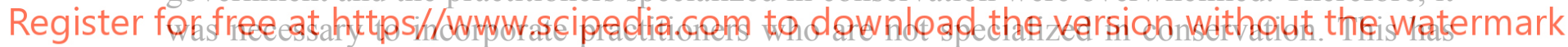

caused that some intervention proposal do not comply with the internationally accepted

conservation principles. In general, non-specialized professionals believe that heritage buildings have a structural behavior similar to modern masonry or reinforced concrete structures. In some cases, this has generated intervention proposals that are not compatible, both structurally and conservation.

For example, some proposals to rebuild the belfry and to strengthen the bell tower of the church shown in figure 1. One of the proposals consisted to rebuild the belfry with reinforced concrete and strength the body of the tower with reinforced concrete walls (fig. 7). But this solution is invasive and irreversible; as well as, change the structural authenticity. In addition, there is incompatibility between the new and old elements. It is not clear how the union between the elements of reinforced concrete and the original elements of stone masonry will be made. The concrete walls do not reach the foundation, which will cause a concentration of stresses in the non-reinforced elements.

Other proposal was to rebuild the belfry with perforated steel plates (fig. 8). In this solution, there is mechanical incompatibility between the steel elements and stone masonry, as well as difficulty of guaranteeing a good anchoring of the metallic elements. High possibility of failure 
of the masonry can occur in the part where the reinforcement ends, due to a local concentrations of stresses in this region. There is a loss of the cultural, artistic and historical values of the church.

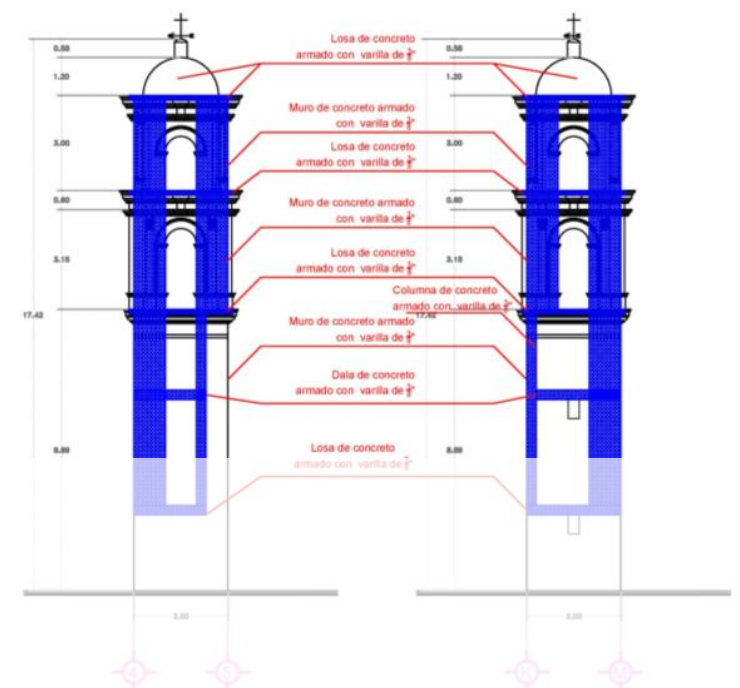

Figure 7: Reinforcement of a bell tower with concrete walls
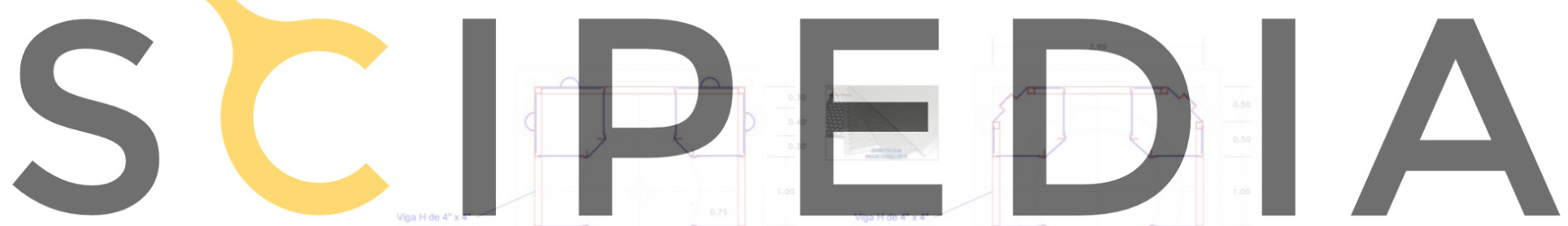

Register for free at https//www.scipedia.com to download the version without the watermark

a)

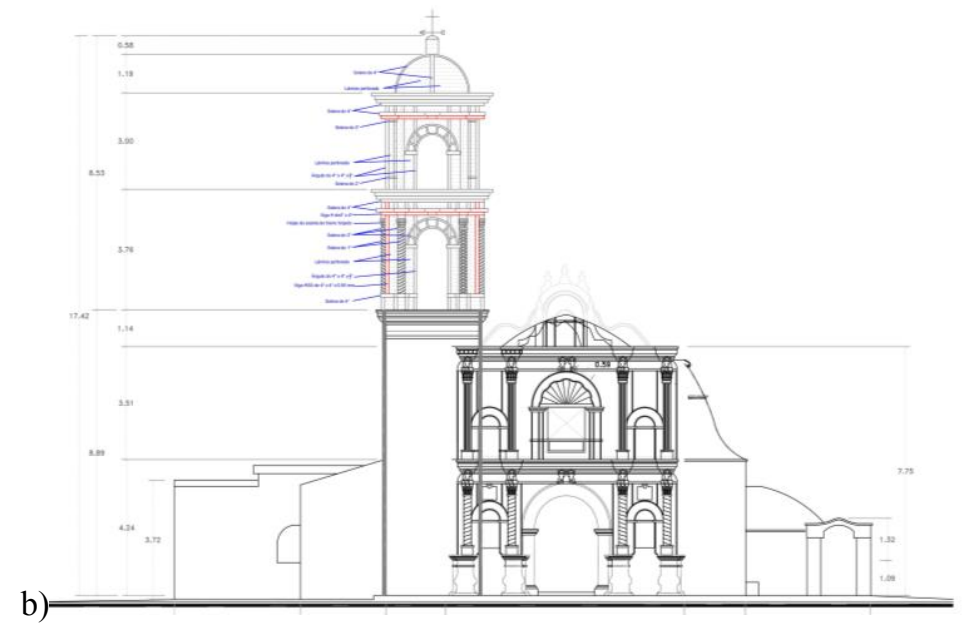

Figure 8: Reconstruction of the belfry with perforated steel plates: a) plan view; b) frontal view 
Finally, the belfry was reconstructed with similar materials (stone masonry) and geometry (two bodies) as the original one. In this case, the cultural, artistic and historic values of the church were conserved. However, as the belfry was reconstructed equal as the original, without any structural upgrade (increase of the structural strength or reduce of seismic forces), it is a high probability to have similar damages in future seismic events.

Another example is the intervention in a cloister of a convent. The cloister is a rectangular two-level floor, attached to the west side of the temple. The vaults of the corridors showed longitudinal cracks. Additionally, significant cracking occurred on the walls (fig. 9a), mainly because the masonry have a poor quality. Rounded stones (pebbles) joined with a lime - sand - soil mortar compose the masonry. These type of stones offer a very low bond with the mortar.

The consolidation of the cracks were realized by injection and the cusci-scusci technique was used (fig. 9b). Similar stones (pebbles) and mortar (lime-sand-soil) was used. Thus, the structural capacity was not upgrade. Furthermore, only the visible cracks due to earthquake damage were repaired. The intervention only aimed to return the structure to its original state regardless of the quality of the material, without improve the structural behavior of the building.
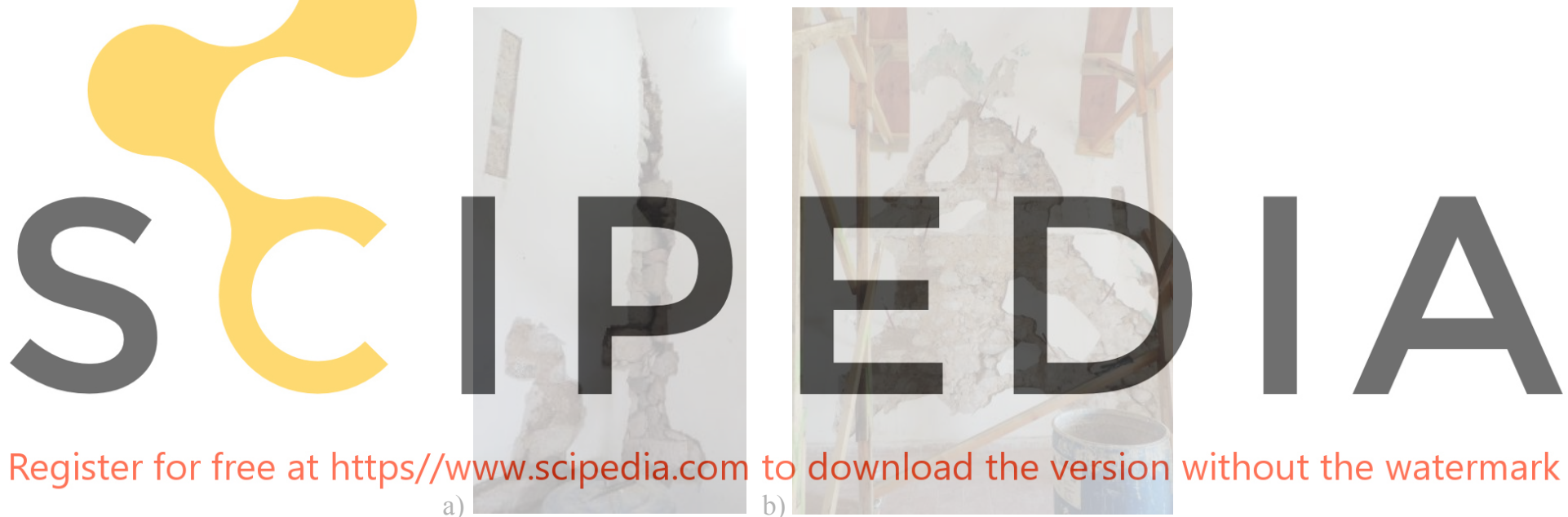

Figure 9: Damage on walls of a cloister: a) cracks; b) consolidation of the cracks

\section{FINAL REMARKS}

- $\quad$ Two large-scale earthquakes hit Mexico on September 7 (Mw 8.2) and 19 (Mw 7.1), 2017 and both left 2,340 damaged architectural heritage buildings throughout the country.

- Due to the large number of damaged heritage buildings, it was necessary to incorporate practitioners who are not specialized in conservation, as well as volunteers from communities with little or no supervision of engineers or architects, first to attend the emergency works and later into structural intervention works.

- There were three main and common errors observed in emergency works were: solutions that do not increase the structural capacity of the building; bad quality of wooden elements, as seen by use of slender vertical elements and/or buckling of these elements; and scarce or excessive shoring system.

- Wood was the most commonly used material in the emergency works, due to its 
versatility, manageability and ease of construction. Steel shoring system or mixed system of steel and wood are also used.

- $\quad$ Scarce shoring system were found on isolated communities and excessive shoring system were found on richer communities.

- It has been detected that the economy of the community has a significant influence on emergency works. In low-income populations, they seek savings in materials that generally lead to poor shoring systems. On the other hand, in richer populations, there may be excessive use of materials.

- In the case of intervention proposals, three common errors were detected: take the same reinforcement considerations as for modern buildings, use of concrete and/or steel elements in order to increase the structural capacity, and reconstruct with the same materials and characteristics as the original structure without increasing its structural capacity.

If the structure is rebuilt with the same materials and characteristics, without increasing its structural capacity, it will have the same weaknesses and problems. Therefore, it will be expected that in future earthquakes there will be the same damages that have occurred in the past.

Therefore, it is necessary to increase the structural capacity of the structure or seek to reduce its seismic demand, in order to avoid future damages.

\section{Acknowledgements.}

for the support provided

Puebla and Morelos,

Goenaga, respectivel

REFERENCES
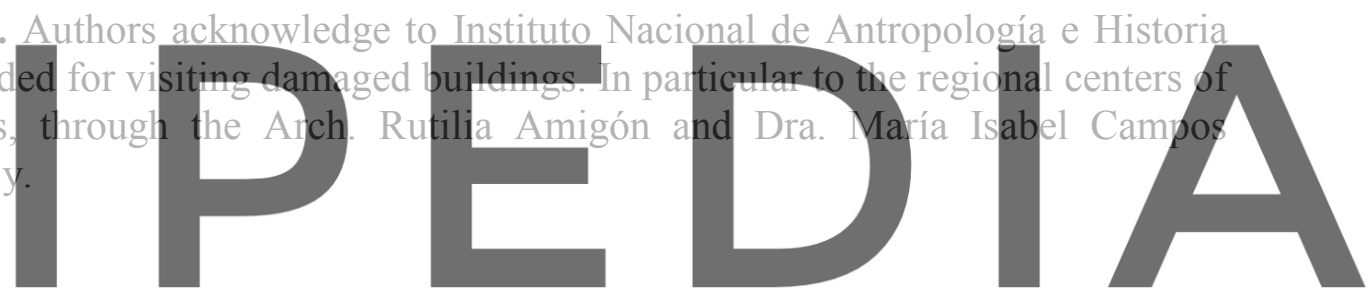

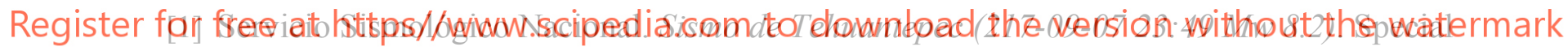

Report, Servicio Sismológico Nacional (2017). Available on:

http://www.ssn.unam.mx/sismicidad/reportes-

especiales/2017/SSNMX_rep_esp_20170907_Tehuantepec_M82.pdf

[2] Servicio Sismológico Nacional. Sismo del día 19 de Septiembre de 2017(Mw 7.1). Special

Report, Servicio Sismológico Nacional (2017). Available on:

http://www.ssn.unam.mx/sismicidad/reportesespeciales/2017/SSNMX_rep_esp_20170919 Puebla-Morelos_M71.pdf

[3] Barker, M., Stone, H., Hammond, D. and O'Connell, J. Field guide for building stabilization and shoring techniques. Department of Homeland Security, USA (2011).

[4] FEMA. Shoring Operations Guide. U.S. Army Corps of Engineers, 2nd Edition, USA (2009).

[5] Corpo Nazionale dei Vigili dei Fuoco. Vademecum STOP. Schede tecniche delle opere provvisionali per la messa in sicurezza post-sisma da parte dei Vigili del Fuoco. Corpo Nazionale dei Vigili del Fuoco - Ministero dell'Interno, Roma (2010).

[6] Grimaz, S. Management of urban shoring during a seismic emergency: advances from the 2009 L'Aquila (Italy) earthquake experience. Bolletino di Geofisica Teorica ed Applicata (2011) 52(2):341-355. 